Author's Original Version (AOV)

This manuscript has not been peer-reviewed

\title{
A Responsiveness-Based Intervention for Female Partners of Male Smokeless Tobacco \\ Users: Changing Supportive Behaviors and Attitudes in a Randomized Clinical Trial
}

\author{
Laura Akers, Ph.D., Oregon Research Institute, Eugene, OR \\ Judy A. Andrews, Ph.D., Oregon Research Institute, Eugene, OR \\ Herbert H. Severson, Ph.D., Oregon Research Institute, Eugene, OR \\ Judith S. Gordon, Ph.D., College of Nursing, University of Arizona, Tucson, AZ
}

Corresponding Author: Laura Akers, Ph.D.,

Oregon Research Institute, 1776 Millrace Drive, Eugene, OR 97403

phone: 541-484-2123 / fax: 541-484-1108 / e-mail: lauraa@ori.org

Conflict of interest statement: The work reported in this paper was supported by a grant from NIDA, R01DA033422. The study sponsor had no role in the study design; collection, analysis, and interpretation of data; writing the report; and the decision to submit the report for publication. The authors declare that they have no conflict of interest.

Ethical approval and informed consent: All procedures performed in studies involving human participants were in accordance with the ethical standards of the Oregon Research Institute Institutional Review Board and with the 1964 Helsinki declaration and its later amendments or comparable ethical standards. This article does not contain any studies with animals performed by any of the authors. Informed consent was obtained from all individual participants included in the study. 


\section{ABSTRACT}

Background: Partner support can play an important role in health behavior change, but wellintentioned supportive behaviors can also generate resistance to change. Previous research found that "perceived partner responsiveness" to support is highest when the supporting partner demonstrates respect, understanding, and caring.

Purpose: Here we explore the hypothesis that exposure to a responsiveness-based intervention leads to improvements in supportive behaviors and attitudes, in the smokeless tobacco (ST) cessation context.

Methods: 1,145 wives/domestic partners of ST users who wanted their male partner to quit tobacco were randomized to intervention or delayed treatment control. Those randomized to intervention received immediate access to the interactive UCare (ㅁnderstanding, $\underline{\text { Caring, }}$ Respect) website and were mailed a printed booklet. Enrollment began in July 2015 and ended in December 2016. Outcome measures were change from baseline to six-week follow-up in behaviors and attitudes/beliefs related to showing respect, understanding, and caring (responsiveness) in the tobacco cessation context, and change in a measure of instrumental (practical) support, and the relation between these variables and intervention exposure.

Results: Changes in the desired direction were observed for the intervention group, as compared to the control group, for the three main outcomes of interest. Effect sizes assessing change were between small and medium. Change in each of the support outcomes was predicted by intervention use.

Conclusions: A brief intervention can train individuals to show greater partner responsiveness toward their partner in the tobacco cessation context, increasing their supportive behaviors and improving their attitudes/beliefs about their partner's tobacco use and the cessation process. 
Trial Registration: ClinicalTrials.gov NCT01885221

Keywords: partner support, social support, responsiveness, tobacco cessation 


\section{INTRODUCTION}

Partner support can play an important role in tobacco cessation, from encouraging the tobaccousing partner to quit, to facilitating their access to quitting resources, to supporting their cessation efforts and sustained long-term abstinence.(1,2,3,4,5) However, well-intentioned but inappropriately framed support from significant others can generate reactance, in which behaviors become more entrenched when the person feels pressured in ways that limit autonomy.(6,7)

Although social support is correlated with successful tobacco cessation, interventions designed to optimize social support have shown mixed results. $(2,8)$ Support may be difficult to manipulate, but it is not a fixed attribute, either within an individual or a relationship. Rather, it is a set of behavioral skills, much like parenting, which can be taught.

The smokeless tobacco (ST) cessation context provides a unique opportunity to study social support in addiction without the complicating effects of gender roles, because the target behavior is an almost exclusively male activity, and their female partners are often highly motivated to encourage them to quit. In an earlier ST cessation study $(9,10)$, we had found that ST users' received positive support from their female partners, and the ratio of positive to negative support - as measured by the Partner Interaction Questionnaire (PIQ-20(1,2,11,12), -- predicted abstinence at 6-month follow-up (odds ratio $=1.29$ for received positive support, C.I. $=1.03$ 1.61)(9). Received positive support also predicted abstinence at 12-month follow-up (odds ratio $=1.43$, C.I. $=1.11-1.84)(10)$. On the basis of these findings, our team conducted a feasibility study (NIH; R21-CA131461) with 522 wives and domestic partners of ST users to see if we could teach the women to increase positive support and decrease negative support while 
encouraging their partners to quit their ST use. Although intervention use was correlated with six-week cessation, the measures we used, including the PIQ-20, did not capture the change in behaviors, skills, beliefs, and attitudes that led to greater cessation for the Intervention group. We thus sought a stronger theoretical framework for partner support in the context of health behavior change.

\section{$\underline{\text { Partner Responsiveness }}$}

Previous research had shown that partner support is not always well received by the recipient. Reis, Clark, and Holmes(13) studied this phenomenon in depth and found that "perceived partner responsiveness" to support is highest under three conditions: (1) the supporting partner is believed to respect and validate the recipient's core qualities, including judgment and decisionmaking; (2) the recipient feels a bond of emotional rapport with the supporting partner and believes the partner understands their perspective and concerns; and (3) the recipient believes the partner will respond to their needs in a caring fashion. Maisel and Gable(14) have found that "responsive" support leads to greater relationship quality and lower recipient anxiety; their research used a composite score of three items: "My partner made me feel like he/she valued my abilities and opinions," "My partner understood me," and "My partner made me feel cared for."

These findings are consistent with research on motivation. Self-determination theory $(15,16)$ has demonstrated that encouraging another's self-initiation and choice can increase their motivation to change, when three social contextual factors are present: "providing a meaningful rationale, acknowledging the behaver's feelings, and conveying choice".(17) Conveying choice is a fundamental way of showing respect for another's autonomy, and acknowledging their feelings shows understanding. 
The partner responsiveness model(13), or "Responsiveness Theory," offers several advantages. First, it provides a framework for previous research on positive and negative behaviors, helping to explain why specific behaviors are best classified as positive or negative, and how these behaviors can be replaced more effectively. For example, the PIQ-20 support item "ask him to quit" is coded as negative because it can be perceived as overstepping the boundaries of his autonomy, whereas "ask him to consider quitting" could be positive if framed in terms of respecting his choices and reflecting the partner's care for the tobacco user. Second, partner responsiveness represents an approach to improving the couple's relationship quality in the tobacco cessation context that can be undertaken unilaterally by one partner, unlike most interventions for improving couple relationship quality (e.g., couples relationship education programs(18); Couples Coping Enhancement Training.(19) Third, the concepts of showing respect, understanding, and caring are easy to convey and make intuitive sense.

We conducted a pilot study confirming that Responsiveness Theory is a good fit for classifying support in this context.(20) Our pilot work resulted in a classification scheme of positive and negative examples for showing respect, understanding, and caring, and provided a framework for the multimedia intervention on which we are reporting in this paper. The intervention, called UCare (for $\underline{\text { Understanding, }}$ Caring, Respect), consisted of an interactive website and printed booklet. The purpose of the intervention was to teach women how to provide Responsivenessinformed support in the ST cessation context, i.e., to respect whether, when, and how their partner wants to quit ST, demonstrate understanding for his perspective and experiences, and show warmth and affection when discussing his tobacco use. Development, use, and perceived 
usefulness of the intervention and its components are described elsewhere.(21) Tobacco cessation outcomes, including the mediating effects of change in support, are forthcoming.

Between July 2015 and December 2016, we recruited 1,145 women over a 15-month period to participate in a randomized clinical trial (RCT) of the UCare intervention. In this paper, we explore the hypothesis that exposure to this responsiveness-based intervention leads to improvements in supportive behaviors and attitudes when encouraging a loved one to quit ST. We report on changes in measures of positive and negative support (both behaviors and attitudes/beliefs for showing respect, showing understanding, and showing caring) between baseline and six-week follow-up, and the relationship between exposure to the intervention and change in support.

\section{METHODS}

This study is registered with ClinicalTrials.gov, \# NCT01885221.

\section{Study Sample and Procedures}

Study recruitment took place entirely online, using demographically targeted Facebook advertising.(22) The 1,145 enrolled women were randomized to receive the intervention immediately $(\mathrm{N}=552)$ or to a delayed treatment control $(\mathrm{N}=593)$, in which participants received intervention access after completing a final follow-up assessment. The number enrolled in the study was based on the power to detect a difference in cessation between the two groups with a power of .80 and alpha of .05 . Randomization took place through the UCare system software, and because this was a health behavior study, there was no blinding. Randomization was done in blocks of eight; the randomization algorithm was known only to the software 
subcontractor and not to the research staff. Study enrollment and data collection occurred 20152017.

Potential participants were first screened online for eligibility. Inclusion criteria were: being the wife or female domestic partner of a male current ST user; interested in having him quit using tobacco; willing to provide a phone number, mailing address, and e-mail address; providing informed consent; and both the woman and the ST user being U.S. or Canadian residents age 18 or older, able to read English, and able to access a computer. Those ineligible to participate were referred to the national tobacco quitline and the ChewFree.com ST cessation website.(23) Eligible participants were invited to complete an informed consent, provide personal contact information, and complete a baseline survey online. Those who met these criteria were randomized to either the UCare Intervention or Delayed Treatment Control condition. The study was approved by the Oregon Research Institute IRB.

\section{The UCare Intervention}

Those assigned to the UCare Intervention condition were given immediate access to the UCare website, and were mailed the UCare booklet. The components of the website were (1) "The Basics," a linear instructional program with options for personal tailoring and printable lists of notes and choices; (2) "My Notebook," in which they could review and print personally relevant sections from “The Basics"; (3) "Quitting Resources,” which focused on ST addiction and methods for cessation, and (4) "Discussion Topics" and (5) "Ask an Expert" for social support. Within "The Basics," three modules provided text information and audio/text illustration about how to provide support during the stages of quitting (planning to quit, quitting, and staying quit), and a fourth module helped the user plan how to talk with her partner about quitting. Each of the 
four modules was organized within the themes of showing respect, showing understanding, and showing caring, with additional materials on stress reduction and self-care for the supporter. The printed booklet reinforced the messages in the website, encouraged participants to use the website, and provided a handy way the women could reassure their partner that the program was not going to try to "make him" quit. The website components and booklet are described in greater detail elsewhere.(21)

\section{$\underline{\text { Follow-Up Assessment Procedures }}$}

At six weeks post-enrollment, all participants were sent an e-mail link to complete a follow-up assessment. After five automated e-mails prompting them to complete the assessment, efforts were made to contact them by phone and text message, with the option of completing the assessment online or by phone. An incentive was offered for completing the assessment $(\$ 20)$. Data collection took place between 2015 and 2017.

\section{$\underline{\text { Measures }}$}

All measures were completed by the participants. The husbands/partners were not asked to complete assessments.

Demographics and tobacco use. The baseline assessment included year of birth, education, race, and Hispanic ethnicity for the participant and her husband/partner; the length of their relationship and whether they were married or in a domestic partnership; her current and past status for smoking and ST use; his current and past smoking status; her estimate of his motivation to quit (8-point scale from not motivated to very motivated); and her estimate of his readiness to quit.(24) The two follow-up assessments included the couple's current relationship status; her 
current smoking and ST use status; his current tobacco use and types; and his length of abstinence if he had quit. If he had not quit, the assessment included whether he had made a serious quit attempt and whether he was able to stay abstinent for 24 hours; types of changes in his tobacco use; and the motivation and readiness items from the baseline survey.

Relationship quality. The participant's overall satisfaction with the relationship was assessed with the four-item version of the Couples Satisfaction Index (CSI-4).(25) Friction in their relationship about his ST use was assessed using a measure patterned after the Issues Checklist. $(26,27)$ A Tobacco Issues Checklist summary variable was then calculated as the number of potentially contentious issues checked (out of five), times the average number of times each issue was discussed in the last two weeks, times the average rated intensity of the discussions. This procedure is recommended by Robin and Weiss for scoring the original Issues Checklist. Also assessed were her comfort in discussing his tobacco use with him (8-point scale from not comfortable to very comfortable) and whether she had recently asked him to quit using ST.

Partner support. In order to capture the relevant aspects of support, we created theory-based measures of partner support corresponding to positive and negative facets of the three responsiveness themes: seven brief measures of supportive behaviors and six brief measures of supportive attitudes/beliefs. The seven behavior measures assessed activities in the past four weeks within the ST-cessation context, covering positive and negative "showing respect," positive and negative "showing understanding," positive and negative "showing caring," and a seventh measure of instrumental (practical) activities focusing on facilitating cessation, e.g., 
"Help your partner think of substitutes for snuff or chew." Within the behavior measures responses used a yes/no format rather than assessing frequency, as we wanted the women to engage in the activity but doing so repeatedly could be counterproductive (e.g., nagging). The six attitude/belief measures assessed attitude toward positive and negative "showing respect," positive and negative "showing understanding," and positive and negative "showing caring." The response format was 5-point Likert scale ranging from strongly disagree to strongly agree.

Items for the initial measures were drawn from many sources, including our previous research (NIH; R21-CA131461), the PIQ-20, and the Support Provided Measure.(28) Previous research on perceived partner responsiveness(14) provided general items for the three responsiveness themes, which were then adapted to the ST cessation context. Items for showing respect were adapted from dyadic goal-setting research, $(6,29,30)$ and from the Health Care Climate Questionnaire,(31) which was based on self-determination theory (e.g., respecting autonomy). Items for showing understanding were adapted from the Davis Interpersonal Reactivity Indexes(32,33) for perspective-taking, empathic concern, and empathic distress.

To refine our initial measures, we conducted a pilot study with 61 participants. Each measure was refined based on item analysis and face validity. Alphas ranged from .52 to .88 ; stability (correlation between $\mathrm{T} 1$ and $\mathrm{T} 2$ scores two weeks apart) ranged from .42 to .88 .

We created two scales, "Summary Respect-Understanding-Caring (RUC) Behaviors" (18 items) and "Summary RUC Attitudes" (14 items) from the 12 responsiveness measures, reverse-scoring 
the negative items. These two scales, along with the measure of instrumental behaviors (4 items), are our primary support outcomes.

\section{Intervention Exposure}

Standard web tracking procedures (time-stamped logs of all page visits, etc.) were used to collect data on all participant activity within the UCare website, and reports were created by our software subcontractor for each participant's use of each relevant component in the periods between the baseline assessment and the day prior to completion of the six-week assessment (or between days 0 and 41 for those not completing the assessments). Booklet use was assessed at the six-week follow-up.

\section{$\underline{\text { Statistical Analyses }}$}

All analyses were conducted using IBM's SPSS Statistics version 23 and 24. Data analysis took place 2017-2018. Using SPSS version 24, we used the Expectation-Maximization (EM) algorithm to impute missing data at six-week follow-up.

Support outcomes. For the full sample $(\mathrm{N}=1088)$, correlations among the summary RUC variables were examined, as was their correlation with instrumental behaviors. Repeated measures analysis of variance, including the time by group interaction, was calculated for the three outcome measures. Effect sizes were calculated for significant outcomes.

Predicting six-week support outcomes from baseline variables. We used hierarchical regressions to predict each of the three main support outcomes (summary respect-understanding-caring ("RUC") behaviors, summary RUC attitudes, and instrumental behaviors). Specifically, after 
controlling for the baseline measure of the support outcome, we entered the blocks in the following order: (1) demographics, (2) the supporter's tobacco use, and (3) other key variables, as listed below. Within each block, we included the main effect of the intervention condition and the interaction between the condition and each of the hypothesized predictors. We then used backward elimination to first eliminate non-significant interactions with the intervention, followed by non-significant main effects. Significant effects in each block were retained in the equation. Significant interactions were decomposed using the techniques presented in Aiken and West.(34)

The first block, demographic variables, included age, education (some college vs. no college), race (white vs. non-white), and ethnicity (Hispanic/Latino vs. non-Hispanic/Latino) for the supporter and the ST user, and the length of their relationship. The second block, tobacco use, consisted of whether the female participant had ever used tobacco. The third block included the readiness to quit "ladder" score, the motivation to quit rating, the participant's rating of her comfort discussing his tobacco use with him, the Couples Satisfaction Index (CSI-4) score, and the Tobacco Issues Checklist summary variable.

Predicting six-week support outcomes from intervention exposure. We used multiple regressions to predict each of the three support outcomes from intervention exposure (defined as completing the website "Basics" or self-reported reading of all of the booklet, or all of the booklet more than once).

\section{RESULTS}


Total enrollment was 1,145 women, of whom 552 were randomized to Intervention and 593 to Delayed Treatment Control. Figure 1 is a CONSORT flow diagram, displaying the numbers of potential and actual participants at each stage of the study.

\section{[insert Figure 1: CONSORT Flow Diagram]}

Characteristics of participants. Table 1 presents summary characteristics for the participants. The sample was largely white, non-Hispanic, and college educated, with a mean age of 43.2 and a mean relationship length of 15.6 years. Results of chi-square comparisons and t-tests revealed no differences between groups in the characteristics of participants at baseline for any of the baseline variables, including demographics, tobacco use, relationship quality, and each of the 13 support measures.

\section{[insert Table 1: Participant Characteristics]}

Attrition at six-week follow-up. Participants randomized to Delayed Treatment were more likely to complete the assessment (66.4\% vs. 52.9\%; p<.001). Baseline variables associated with higher levels of completing the six-week assessment were participant age (those completing were younger, mean age $=42.35$ vs. $44.43, \mathrm{t}=-3.548, \mathrm{p}<.001)$, partner age (those completing were partnered with younger men, mean age $=43.71$ vs. $46.35, \mathrm{t}=-4.604, \mathrm{p}<.001$ ) relationship length (those completing had been in this relationship for a shorter length of time 14.43 years vs. 17.33 years, $\mathrm{t}=-4.725, \mathrm{p}<.001$ ), partner education (the men with women completing the assessment were more likely to have completed some college, $70.6 \%$ vs. $64.7 \%$, chi-square $=4.340, \mathrm{p}$ $=.038$ ), perceived readiness to quit (those completing the survey judged their partner more ready to quit, 5.12 vs. $4.76, \mathrm{t}=2.645, \mathrm{p}<.01)$. Participant age and partner age were highly correlated $(\mathrm{r}$ 
$=.89, \mathrm{p}<.01)$, and both were highly correlated with relationship length $(\mathrm{r}=.66$ for the participant and .68 for the partner, $\mathrm{p}<.01)$.

Support outcomes. Change in the support measures as a function of the intervention is shown in Table 2. Results suggest changes in the desired direction for the intervention group, as compared with the control group, for the three main outcomes of interest: the summary variables for RUC behaviors, RUC attitudes, and instrumental behaviors. At both baseline and six-week follow-up, RUC behaviors was correlated with both RUC attitudes ( .35 at baseline, .44 at six weeks, $\mathrm{p}<$ .001 ) and instrumental behaviors (.38 at baseline, .43 at six weeks; $p<.001$ ), although RUC attitudes and instrumental behaviors were not correlated. Each outcome variable's baseline value was also correlated with its six-week value (.60 for RUC behaviors, .79 for RUC attitudes, and .58 for instrumental behaviors, $\mathrm{p}<.01)$. Using Cohen's $(35)$ guidelines for interpreting effect sizes for partial eta squared statistics of $0.01=$ small, $.06=$ medium, and $.14=$ large, we can conclude that being randomized to the intervention produced a small effect on RUC behaviors, a small-to-medium effect on instrumental behaviors, and a medium effect on RUC attitudes. An analysis comparing only participants who completed the intervention ( $N=209)$ versus control had similar results.

[insert Table 2: Change in Responsiveness-Based Support Variables at Six-Week FollowUp]

Predictors of support outcomes. As shown in table 3, randomization to the intervention condition predicted change in each of the respective outcomes. Across conditions, variables related to supporter and partner age, supporter education, relationship length, the supporter's previous 
tobacco use, her beliefs about his readiness and motivation to quit, and relationship quality variables were related to change in support outcomes. The significant interaction between condition and education in the prediction of change in attitudes was decomposed centering at 1.25standard deviations to assess the effect for those with high education and +1.25 standard deviations to assess low education.(34) The intervention was effective at changing attitudes for those with average (see Table 3 ) or high education (standardized beta $=.160, \mathrm{p}<.001$ ), but was not effective for those with low education (standardized beta $=.040, \mathrm{p}=.144$ ).

[insert Table 3. Baseline Predictors of Six-Week Change in Three Support Outcomes Results of Hierarchical Regression]

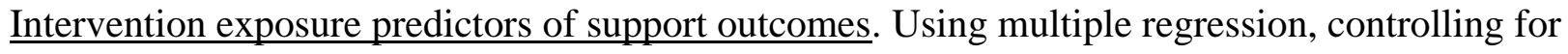
the T1 level of the outcome, completion of the intervention (defined as using the website "Basics" or reading the booklet) predicted all T3 outcomes (standardized beta for responsiveness behaviors $=.169$, for responsiveness attitudes $=.167$, and for instrumental behaviors $=.208, \mathrm{p}$ values $<.001)$. Hence, completion of the intervention was associated with change in each of the three support outcomes.

\section{DISCUSSION}

Use of the UCare website and booklet improved the supportive behaviors and attitudes of women who want their husband/partner to quit his use of smokeless tobacco. The changes included an increase in behaviors and attitudes for showing respect, understanding, and caring to their partner in the ST cessation context, as well as an increase in instrumental behaviors (practical cessation support). The findings support our approach to using partner responsiveness as a framework for 
teaching support skills to women who want their partners to quit ST. Our results also have relevant for advancing conceptual frameworks of family and peer support for tobacco cessation more generally.(8)

Study participants were all female. Most of the participants had attended college and thus were relatively well-educated; the vast majority were white and non-Hispanic, which matches the general demographics of ST users. Whether this approach will work as well with men, with the less well educated, and with members of ethnic minorities remains to be studied.

Participants were counted as having received the intervention if they completed the full "Basics" component of the website or reported reading the mailed booklet. Although they received weekly e-mailed reminders to complete the Basics, many women did not do so. We will continue to explore ways to encourage participants to complete the key treatment activities when they have chosen to enroll in an online study.

\section{$\underline{\text { Limitations }}$}

The present study uses data from a six-week follow-up assessment and does not demonstrate the degree to which the attitudes and behaviors are retained over time. Further, it should be noted that there may be relevant aspects of support that our measures are not assessing. For example, we have measures only of support provided, not support received (the perspective of the male ST user). It would have been prohibitively difficult to recruit enough ST users to provide data, as many of them were not ready to quit and some of them would not even have been aware that their wives were participating in the study. 
Only $59.2 \%$ of enrolled participants completed the 6 -week follow-up assessment. The $40 \%$ attrition rate appears typical of recent mHealth studies (e.g., 41.4\% at one month for Muñoz et al.(36); $45.3 \%$ at six weeks for Severson et al.(23)). The ease with which participants can ignore e-mails and block phone calls may contribute to the low response rates. Strategies that may improve them include increasing the participants' sense of personal connection to the study with greater personal contact and reducing the perceived response burden for survey completion.

Moreover, the Delayed Treatment participants were likely to complete the six-week follow-up assessment than Intervention participants. A systematic review and meta-analysis of 60 health behavior change trials found an overall $10 \%$ higher attrition rate for intervention versus control.(37) These authors speculated that since intervention participants are not blind to condition they will have higher expectations than control participants. If those expectations are not met, they may be less likely to complete follow-up assessments than those whose expectations are lower. Another possible explanation is that those randomized to delayed treatment have an incentive to complete the follow-up assessments (a requirement for eventually receiving the intervention), which those already receiving the intervention do not share.

\section{CONCLUSIONS}

The UCare intervention, based on Responsiveness Theory, shows promise for training supporters to help a loved one quit their use of tobacco. The intervention increased rates of showing respect, understanding, and caring to the ST user in the context of his tobacco use, along with instrumental support. It also increased the participants' attitudes for showing respect, 
understanding, and caring, which are especially relevant for ST users who are not yet ready to quit.

More broadly, the results of this study suggest that the responsiveness framework could be considered for other contexts in which one partner wants to learn how better to support the other, whether for specific health behavior change efforts or for longer term management of chronic diseases. The principles of showing respect, understanding, and caring may be fundamental to relationship quality, and our work indicates that a brief intervention can produce positive changes in both behaviors and attitudes. 


\section{ACKNOWLEDGMENTS}

This research was funded by grant R01DA033422 from the National Institute on Drug Abuse. The research presented in this paper is that of the authors and does not reflect the official policy of the NIH. Dr. Akers wrote the first draft of the manuscript, and all authors provided substantive feedback. Dr. Andrews supervised the data analysis. The authors would like to thank InterVision Media and Zoe Brady for their help in developing the UCare intervention, Chris Widdop and Melissa Peterson for data analysis, and Katie Clawson for assistance with the UCare booklet and manuscript preparation. We appreciate the helpful feedback provided by Christi Patten and Ed Lichtenstein. 


\section{REFERENCES}

1. Cohen S, Lichtenstein E. Partner behaviors that support quitting smoking. J. Consult Clin Psychol. 1990;58(3):304-309. DOI: 10.1037/0022-006X.58.3.304

2. Park EW, Schultz JK, Tudiver F, Campbell T, Becker L. Enhancing partner support to improve smoking cessation. Cochrane Database Syst Rev. 2004(3):Cd002928. DOI: 10.1002/14651858.CD002928.pub2.

3. Patten CA, Offord KP, Hurt RD, et al. Training support persons to help smokers quit: A pilot study. Am J Prev Med. 2004;26(5):386-390. DOI: https://doi.org/10.1016/j.amepre.2004.02.008.

4. Patten CA, Smith CM, Brockman TA, et al. Support person intervention to promote smoker utilization of the QUITPLAN Helpline. Am J Prev Med. 2008;35(6):S479-S485. DOI: 10.1016/j.amepre.2008.09.003.

5. Patten CA, Smith CM, Brockman TA, et al. Support-person promotion of a smoking quitline: a randomized controlled trial. Am J Prev Med. 2011;41(1):17-23. DOI: 10.1016/j.amepre.2011.03.012.

6. Fisher JD, Nadler A, Whitcher-Alagna S. Recipient reactions to aid. Psychol Bull. 1982;91(1):27-54. DOI: 10.1037/0033-2909.91.1.27.

7. Rohrbaugh MJ, Shoham V, Trost S, Muramoto M, Cate RM, Leischow S. Couple dynamics of change-resistant smoking: toward a family consultation model. Fam Process. 2001;40(1):15-31.

8. Westmaas JL, Bontemps-Jones J, Bauer JE. Social support in smoking cessation: reconciling theory and evidence. Nicotine Tob Res. 2010;12(7):695-707. DOI: 10.1093/ntr/ntq077.

9. Lichtenstein E, Andrews J, Barckley M, Akers L, Severson H. Women helping chewers: Partner support and smokeless tobacco cessation. Health Psychol. 2002;21(3):273-278. DOI: 10.1037/0278-6133.21.3.273.

10. Danaher BG, Lichtenstein E, Andrews JA, Severson HH, Akers L, Barckley M. Women helping chewers: Effects of partner support on 12-month tobacco abstinence in a smokeless tobacco cessation trial. Nicotine Tob Res. 2009;11(3):332-335. DOI: 10.1093/ntr/ntn022.

11. Mermelstein R, Cohen S, Lichtenstein E, Baer J, Kamarck T. Social support and smoking cessation and maintenance. J Consult Clin Psychol. 1986;54(4):447-453. DOI: doi: 10.1037/0022-006X.54.4.447.

12. Roski J, Schmid LA, Lando HA. Long-term associations of helpful and harmful spousal behaviors with smoking cessation. Addict Behav. 1996;21(2):173-185. DOI: https://doi.org/10.1016/0306-4603(95)00047-X.

13. Reis HT, Clark MS, Holmes JG. Perceived partner responsiveness as an organizing construct in the study of intimacy and closeness In: Mashek DJ, Aron A, eds. Handbook of Closeness and Intimacy. Mahwah, NJ: Lawrence Erlbaum Assoc; 2004:201-225.

14. Maisel NC, Gable SL. The paradox of received social support: the importance of responsiveness. Psychol Sci. 2009;20(8):928-932. DOI: 10.1111/j.1467-9280.2009.02388.x.

15. Deci E, Ryan RM. Intrinsic motivation and self-determination in human behavior. New York, NY: Springer US; 1985.

16. Deci EL, Ryan RM. The "what" and "why" of goal pursuits: Human needs and the selfdetermination of behavior. Psychol Inq. 2000;11(4):227-268. DOI:

10.1207/S15327965PLI1104_01. 
17. Deci EL, Eghrari H, Patrick BC, Leone DR. Facilitating internalization: The selfdetermination theory perspective. J Pers. 1994;62(1):119-142. DOI: doi:10.1111/j.14676494.1994.tb00797.x.

18. Rauer AJ, Adler-Baeder F, Lucier-Greer M, Skuban E, Ketring SA, Smith T. Exploring processes of change in couple relationship education: predictors of change in relationship quality. J Fam Psychol. 2014;28(1):65-76. DOI: 10.1037/a0035502.

19. Ledermann T, Bodenmann G, Cina A. The efficacy of the couples coping enhancement training (CCET) in improving relationship quality. J Soc Clin Psychol. 2007;26(8):940-959. DOI: $10.1521 /$ jscp.2007.26.8.940.

20. Akers L, Gordon JS, Brady Z, Andrews JA, Severson HH. Utility of responsiveness theory for classifying supportive behaviors to enhance smokeless tobacco cessation. Nicotine Tob Res. 2016;18(5):1150-1156. DOI: 10.1093/ntr/ntv282.

21. Akers L, Andrews JA, Gordon JS. Use and perceived acceptability of a multimedia support skills intervention for female partners of male smokeless tobacco users. JMIR Formative Res. In press.

22. Akers L. Effective Facebook advertising strategies for an online RCT recruitment. Submitted.

23. Severson HH, Gordon JS, Danaher BG, Akers L. ChewFree.com: evaluation of a Webbased cessation program for smokeless tobacco users. Nicotine Tob Res. 2008;10(2):381391. DOI: $10.1080 / 14622200701824984$.

24. Biener L, Abrams DB. The Contemplation Ladder: validation of a measure of readiness to consider smoking cessation. Health Psychol. 1991;10(5):360-365.

25. Funk JL, Rogge RD. Testing the ruler with item response theory: increasing precision of measurement for relationship satisfaction with the Couples Satisfaction Index. J Fam Psychol. 2007;21(4):572-583. DOI: 10.1037/0893-3200.21.4.572.

26. Prinz RJ, Foster S, Kent RN, O'Leary KD. Multivariate assessment of conflict in distressed and nondistressed mother-adolescent dyads. J Applied Behav Anal. 1979;12(4):691-700. DOI: 10.1901/jaba.1979.12-691.

27. Robin AL, Weiss JG. Criterion-related validity of behavioural and self-report measures of problem-solving communication skills in distressed and non-distressed parent-adolescent dyads. Behav Assess. 1980;2:339-352.

28. Thomas JL, Patten CA, Offord KP, Decker PA. Preliminary findings on the development of a measure of supportive behaviors provided by support persons to help someone stop smoking. J Behav Med. 2004;27(5):507-523. DOI: 10.1023/B:JOBM.0000047613.26632.f4.

29. Chartrand TL, Dalton AN, Fitzsimons GJ. Nonconscious relationship reactance: When significant others prime opposing goals. J Exp Soc Psychol. 2007;43(5):719-726. DOI: 10.1016/j.jesp.2006.08.003.

30. Kappes HB, Shrout PE. When goal sharing produces support that is not caring. Pers Soc Psychol Bull. 2011;37(5):662-673. DOI: 10.1177/0146167211399926.

31. Williams GC, Gagne M, Ryan RM, Deci EL. Facilitating autonomous motivation for smoking cessation. Health Psychol. 2002;21(1):40-50.

32. Davis M. A multidimensional approach to individual differences in empathy. JSAS Cat Select Doc Psychol. 1980;10:85.

33. Davis MH. Measuring individual differences in empathy: Evidence for a multidimensional approach. J Pers Soc Psychol. 1983;44(1):113-126. DOI: doi:/10.1037/0022-3514.44.1.113. 
34. Aiken LS, West SG. Multiple regression: Testing and interpreting interactions. Newbury Park, London: Sage Publications, Inc.; 1991.

35. Cohen J. Statistical power analysis for the behavioral sciences. Hillsdale NJ: Lawrence Erlbaum Associates; 1988.

36. Muñoz RF, Leykin Y, Barrera AZ, Brown CH, Bunge EL. The impact of phone calls on follow-up rates in an online depression prevention study. Internet Interv. 2017;8:10-14. DOI: https://doi.org/10.1016/j.invent.2017.02.001.

37. Crutzen R, Viechtbauer W, Spigt M, Kotz D. Differential attrition in health behaviour change trials: a systematic review and meta-analysis. Psychol Health. 2015;30(1):122-134. DOI: $10.1080 / 08870446.2014 .953526$. 
List of Figures

1. CONSORT Flow Diagram 


\section{Figure 1. CONSORT Flow Diagram.}

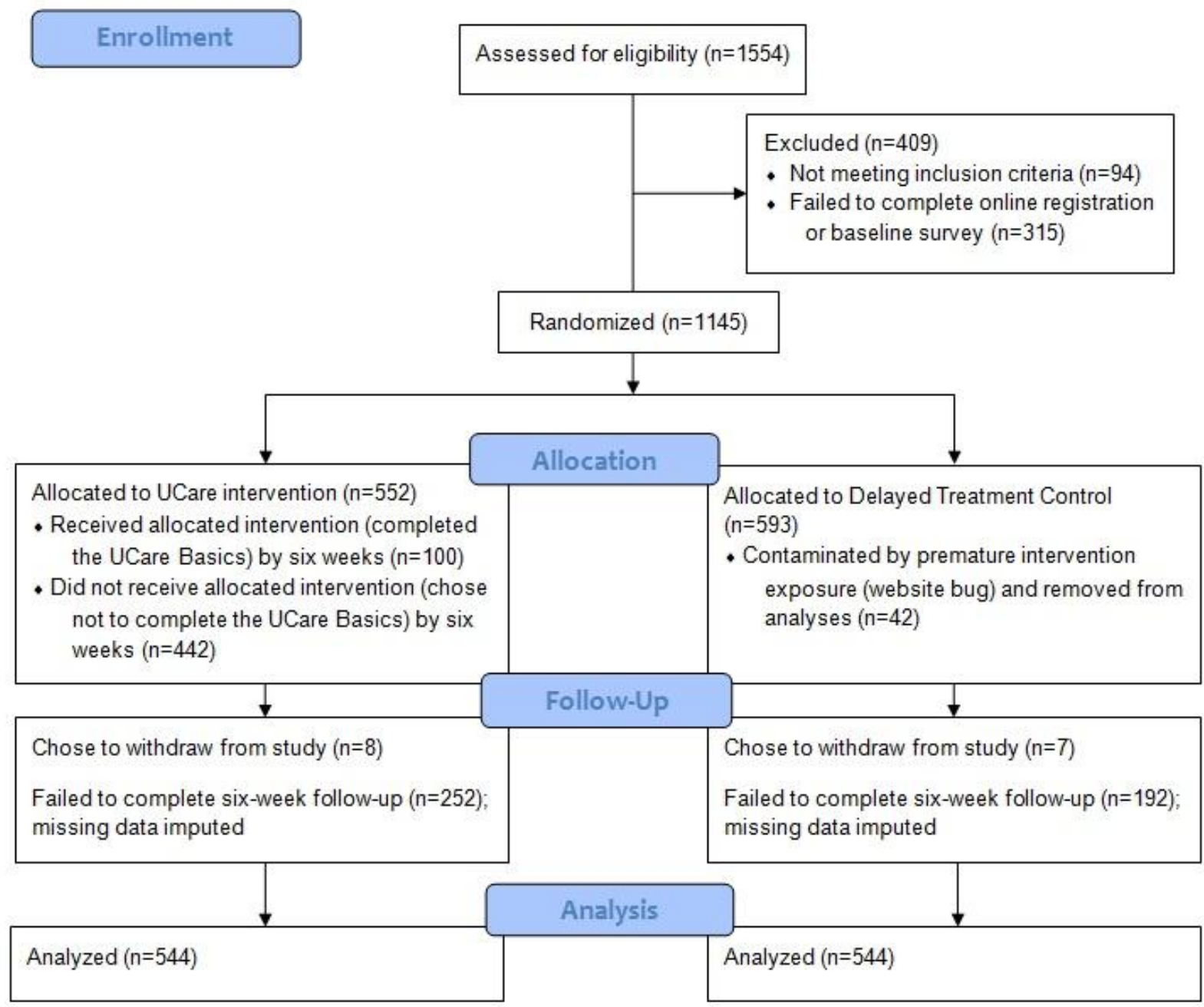


Table 1. Participant Characteristics $(\mathrm{N}=1145)$

\begin{tabular}{|l|c|}
\hline \multicolumn{2}{|l|}{ Demographics } \\
\hline $\begin{array}{l}\text { Gender (\% female, inclusion } \\
\text { criterion) }\end{array}$ \\
\hline Age & 43.2 years (s.d. 9.5) \\
\hline Race (\% white) & $95.3 \%$ \\
\hline Ethnicity (\% non-Hispanic) & $96.3 \%$ \\
\hline Education (some college completed) & $87.8 \%$ \\
\hline Tobacco Use Status & \\
\hline Current smoker & $2.0 \%$ \\
\hline Former smoker & $23.2 \%$ \\
\hline Current chewer & $0.4 \%$ \\
\hline Former chewer & $0.4 \%$ \\
\hline Ever use tobacco & $25.6 \%$ \\
\hline Relationship Status & \\
\hline Married (vs. living with partner) & $93.4 \%$ \\
\hline How long in committed relationship & 15.6 years (s.d. 10.3) \\
\hline Couples Satisfaction Index distress & $37.8 \%$ \\
\hline
\end{tabular}


Table 2. Change in Responsiveness-Based Support at Six-Week Follow-Up

\begin{tabular}{|c|c|c|c|c|c|c|}
\hline \multirow[b]{2}{*}{ Measure } & \multicolumn{2}{|c|}{$\begin{array}{c}\text { Delayed-Treatment } \\
\text { Control } \\
(\mathrm{N}=544)\end{array}$} & \multicolumn{2}{|c|}{$\begin{array}{l}\text { Intervention } \\
(\mathrm{N}=544)\end{array}$} & \multirow[t]{2}{*}{$\begin{array}{l}\text { F value, } \\
\text { Time x } \\
\text { Condition }\end{array}$} & \multirow[t]{2}{*}{$\begin{array}{l}\text { Effect Size: } \\
\text { Partial Eta } \\
\text { Squared }\end{array}$} \\
\hline & Baseline & 6 Weeks & Baseline & 6 Weeks & & \\
\hline R-U-C ${ }^{\mathrm{a}}$ Behaviors & $\begin{array}{r}9.39 \\
(4.16)\end{array}$ & $\begin{array}{l}11.26 \\
(3.95)\end{array}$ & $\begin{array}{r}9.67 \\
(4.09)\end{array}$ & $\begin{array}{l}12.39 \\
(3.54)\end{array}$ & $15.57 * * *$ & 0.014 \\
\hline $\begin{array}{l}\text { Instrumental } \\
\text { Behaviors }\end{array}$ & $\begin{array}{r}1.27 \\
(1.45)\end{array}$ & $\begin{array}{r}1.72 \\
(1.35)\end{array}$ & $\begin{array}{r}1.38 \\
(1.44)\end{array}$ & $\begin{array}{r}2.28 \\
(1.24)\end{array}$ & $34.26^{* * *}$ & 0.031 \\
\hline R-U-C ${ }^{\mathrm{a}}$ Attitudes & $\begin{array}{l}42.41 \\
(7.71)\end{array}$ & $\begin{array}{l}42.77 \\
(6.95)\end{array}$ & $\begin{array}{l}42.05 \\
(7.20)\end{array}$ & $\begin{array}{l}44.83 \\
(6.52)\end{array}$ & $80.15^{* * *}$ & 0.069 \\
\hline
\end{tabular}

$* * * \mathrm{p} \leq .001 ; * \mathrm{p}<.05$. Repeated measures ANOVA $\mathrm{x}$ group interaction.

${ }^{\text {a }}$ Composite score for Respect-Understanding-Caring, with negative variables reverse-scored. 
Table 3. Baseline Predictors of Six-Week Change in Three Support Outcomes - Results of Hierarchical Regression $(\mathrm{N}=1088)$

\begin{tabular}{|c|c|c|c|c|c|c|}
\hline \multirow[t]{2}{*}{ Baseline Variable } & \multicolumn{2}{|c|}{$\begin{array}{c}\text { Summary Respect- } \\
\text { Understanding-Caring } \\
\text { Behaviors } \\
\end{array}$} & \multicolumn{2}{|c|}{$\begin{array}{c}\text { Summary Respect- } \\
\text { Understanding-Caring } \\
\text { Attitudes } \\
\end{array}$} & \multicolumn{2}{|c|}{$\begin{array}{c}\text { Instrumental } \\
\text { Behaviors }\end{array}$} \\
\hline & $\begin{array}{r}\text { Standardized } \\
\text { Beta }\end{array}$ & $\mathrm{p}$-value & $\begin{array}{r}\text { Standardized } \\
\text { Beta }\end{array}$ & $\mathrm{p}$-value & $\begin{array}{r}\text { Standardized } \\
\text { Beta }\end{array}$ & p-value \\
\hline $\begin{array}{l}\text { Measure of } \\
\text { Outcome }\end{array}$ & .547 & $.000^{* * *}$ & .728 & $.000 * * *$ & .499 & $.000^{* * * *}$ \\
\hline Condition & .075 & $.0010 * *$ & .100 & $.000 * * *$ & .114 & $.000 * * *$ \\
\hline Supporter Age & .074 & $.019 *$ & & & & \\
\hline ST User Age & & & .071 & $.003 * *$ & -.089 & $.000 * * *$ \\
\hline $\begin{array}{l}\text { Supporter Highest } \\
\text { Education Level }\end{array}$ & .056 & $.028 *$ & .011 & .653 & -.086 & $.000^{* * * *}$ \\
\hline $\begin{array}{l}\text { Condition } \mathrm{x} \\
\text { Supporter Highest } \\
\text { Education Level }^{\mathrm{a}}\end{array}$ & & & .068 & .006 & & \\
\hline $\begin{array}{l}\text { ST User Highest } \\
\text { Education Level }\end{array}$ & -.073 & $.004 * *$ & & & & \\
\hline $\begin{array}{l}\text { Relationship } \\
\text { Length }\end{array}$ & -.158 & $.000^{* * *}$ & -.118 & $.000 * * *$ & & \\
\hline $\begin{array}{l}\text { Supporter Ever } \\
\text { Use Tobacco }\end{array}$ & & & .144 & $.000^{* * *}$ & -.053 & $.027^{*}$ \\
\hline Readiness Ladder & -.098 & $.009 * *$ & & & & \\
\hline Motivation to Quit & .076 & $.044 *$ & & & & \\
\hline $\begin{array}{l}\text { Couple } \\
\text { Satisfaction Index } \\
\text { (CSI-4) }\end{array}$ & .134 & $.000^{* * * *}$ & & & & \\
\hline $\begin{array}{l}\text { Tobacco Issues } \\
\text { Summary (Topic- } \\
\text { Related Friction) }\end{array}$ & & & -.069 & $.000 * * *$ & .094 & $.000^{* * * *}$ \\
\hline $\begin{array}{l}\text { Supporter Comfort } \\
\text { Discussing ST Use } \\
\text { with User }\end{array}$ & & & & & .118 & $.000^{* * * *}$ \\
\hline
\end{tabular}

Statistical significance: ${ }^{*} \mathrm{p}<0.05,{ }^{* *} \mathrm{p}<0.01, * * * \mathrm{p}<0.001$.

${ }^{a}$ Highest Education is centered at the mean. 